\title{
Aging and Architecture Design Aids by Integral 'Age-Proof' Housing Models
}

\author{
Peter Schmid $^{1}$, Gabriella Pal-Schmid ${ }^{2}$ \\ ${ }^{1}$ Faculty of Architecture, Building, and Planning, Eindhoven University of Technology, \\ Eindhoven, The Netherlands \\ ${ }^{2}$ Research Education Design, Consultancy, Eindhoven, The Netherlands \\ *Corresponding author (peter.schmid.ps@gmail.com)
}

\begin{abstract}
Purpose: The aim was to offer integral design aids for 'age-proof' housing. The main goal is to enable architectural designers to develop housing concepts of a higher than usual quality for aging users. Easy-to-follow models as design aids were developed in the context of R\&D. These models indicate what to avoid, where protection is needed, and how to improve design in order to support aging people in their home. Those models are the central theme of the paper. Method: Systematic integral design (Integral Bio-Logical Architecture - IBA) and model building, particularly for architectural concepts that develop devises or means according to principles of repetition and worldwide application of method of holistic participation (MHP). Results \& Discussion: We focus on elementary conditions to underpin the residents staying healthy and reaching old age, based on a proper and vital built environment. We do not elaborate on possible installations of valuable mechatronics or robotics for resident welfare. We discuss some design aids where the above mentioned design development methods were successfully used. We chose to focus on the principal conditions that determine the quality of sound architecture in relation to health, sustainability, and aging of residents and users. Aging of architecture is an historical objective in terms of interior, room, building, and town. Aging within architecture deals with the residents as principal participants. We conclude our systematically devised research approach by deducing models that can be used as check instruments and integral design aids for 'age-proof' housing and that offer practical applications in the housing design process as well as being a useful topic for multidisciplinary discussion.
\end{abstract}

Keywords: 'Age-Proof' Housing Model, Architecture and Aging, Integral Design Aids

\section{INTRODUCTION}

Within the broad fields of work, leisure, care, robotics, and construction for aging we go to focus on construction of housing, proper for its occupants while aging. In other words, housing and daily living are the main themes of this contribution. Even this field of housing or architecture and aging is a quite wide one, in which we distinguish three characteristic relations:

1 - Aging of architecture itself is an area of interest and the competence of history, and certainly an important item in the light of durability and sustainability. Architecture's age is old as human building culture and as such an essential part of our 'Kulturlandschaft'. Architectural objects can be temporarily, durable, or sustainable. Thus the age of these objects is an important economic, ecological, and cultural factor as well.

2 - Aging with architecture means aging of those people, who - creatively - are dealing with architecture. Some statistics concerning the reached age of architects were made - now and then and in some countries. A whole overview still is missing. However, it seems there is quite a significant number of architects and designers, who reached a relatively high age. One of my own respected teachers - Clemens Holzmeister - was active as architect until his late nineties. Millions of visitors enjoyed the Festspiel- haus and Felsenreitschule in Salzburg, designed by him. Further impressive examples are: the Dutch architect Hendrikus Theodorus Wijdeveld, who around his 100th birthday published a book 'Mijn eerste eeuw' (My First Century); and Grete SchütteLihotzky, designer of the famous Frankfurter Küche, reached also more then 100 years of age.

3 - Aging within architecture might be the humanly most important relation between aging and architecture - certainly for the dwellers or occupants. Because of this reason, we go to present design aids for 'age-proof' housing in order to make housing and instrument and element of service, which supports us in the period of increasing aging.

The presented design aids, also useful as check or ranking tools, are models, which were built on the principles of Integral Bio-Logical Architecture - IBA, a theory, which is characterized by special attention for environment as well as health in a holistic approach. IBA - studies, - research projects, and - practical applications for proposed and realized buildings started in the second half of the 1960ties ${ }^{3,6,8}$.

The increasing call for more and better dwellings, particularly for aging people, who mostly would prefer staying in their own living environment to which they are accommodated and used, cannot be overlooked anymore ${ }^{1}$. It is therefore an important task to build - 'age-proof' dwellings and to refurbish existing 
dwellings to transform them into 'age-proof' ones, if they are not.

\section{Structure of the Design Aids}

Buildings are necessary for survival, certainly in the less paradise-like climate zones of the planet, but also the reason for the complex and many-sided Sick-Building-Syndrome. In extreme cases: a building can kill its inhabitants, not only indirectly as a consequence of natural catastrophes, like earth quakes, but also directly as a consequence of using toxic building materials, or the lack of ventilation. Designing buildings gives a high responsibility to architects, planners, and building engineers, but also to building components producers and suppliers, contractors, housing estates, and politicians.

In this contribution we focus on the rough and basic conditions within buildings, which can help the inhabitants to stay healthy, or to recover in case of proper refurbishment, and to become older, because of a vital built environment. We don't deal with possible installations of valuable mechatronics or robotics for the welfare of occupants. We discuss the main conditions what determine the 'material' quality of a sound architecture in relation to health and aging of dwellers and users.

Inherent in all following models is a 'strategy' of 1 - avoiding a lack, or short coming of the in the models mentioned qualifications (see the next paragraph);

2 - protecting the inhabitants against circumstances, which could or will be uncomfortable for them, or even heart them, by fulfilling the desirable qualities;

3 - improving the qualifications, for example in existing dwellings in order to support, or increase wellbeing and health.

Experience in designing and realizing buildings and their interior lead to the insight and conclusion that there are eight quality factors of high importance, which determine the quality of the whole including quality of life of the dwellers.

1 - indoor climate in terms of temperature, humidity, air / ventilation, light, and sound;

2 - surface of floors, walls, ceilings, etc. in terms of color, texture, thermal accumulation and conduction;

3 - access, or at least outlook to an outdoor area with plants, animals, people;

4 - save, secure, and ergonomically proper design, layout, equipment, and furniture;

5 - all applied materials for construction and completion: allergic-free and toxic-free;

6 - electro-magnetic neutral field;

7 - practical functionality, a suitable translation of the needs in rooms, for equipment, and furnishing;

8 - harmonious proportions in terms of patterns and colors (except the value of a certain heritage in the interior counts higher).

\section{Methods OF JUdGMENT}

For how to judge qualities and how to forecast, or predict qualities of a designed, proposed, or demanded project and even of an executed project, we don't have clear answers (yet).

Because of this reason we distinguish different approaches of ranking, or evaluating qualities - particularly in architecture:

1 - There is the broadly used subjective judgment, which often has strong influence on decisions and choices concerning qualities. Dependent on the 'authority' of the decision-making persons, many clients and residents can be touched - positively, or - even often - also negatively. Subjective judgment might be the usual way for 'private' decisions.

2 - In order to get a more 'democratic' solution, there is the possibility of an inter-subjective judgment, based on the impressions or opinions of a larger preferably representative - number of respondents. Such a ranking process can be done systematically, and can lead to guidelines, which actually continuously should be under control.

3 - Measurable and measured parameter - if they are available and applicable - have a peculiar heavy weight in arguing and decision-making concerning various constellations and configurations of buildings and their interiors in the broadest sense. However, not all of the quality factors are measurable, still some (inter/subjective) interpretation is needed for choices between various possibilities.

Having recognized the possibilities and limits of ranking and relativity of judgment, we have to 'confess' that there is always some wisdom in combination with empathy needed in order to optimize decisions for a proper built environment ${ }^{3}$.

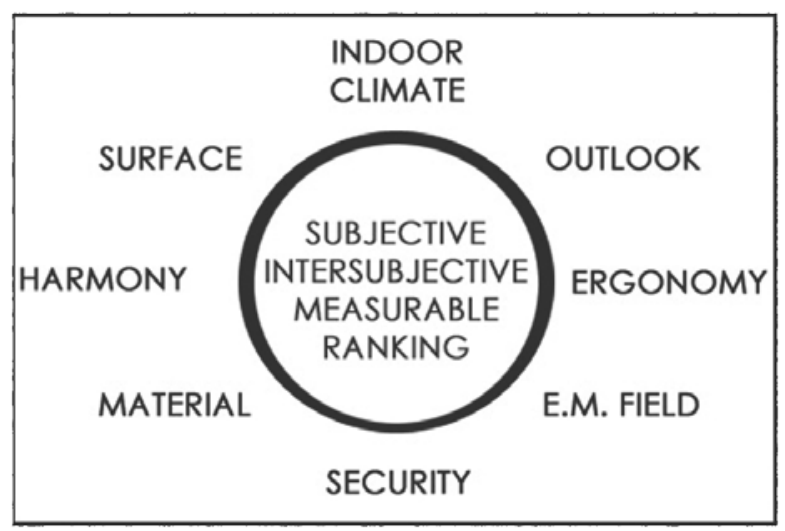

Figure 1. Basic pattern of 'Age-Proof' Housing Models AHM for various design aids ('sub' models) related to physical, psychological, and spiritual expectations and requests of aging occupants, to be used in the various factor-focused models

The factors that influence the quality of the built environment on the scale of dwellings are systematized in categories, and visualized in models. Those mod- 
els bring the relevant influences under attention of designers, decision-makers, and clients, and they are useful for consultation about desirable qualities. The different possibilities of ranking and judgment can be adopted and they mutually can adjoin opinions, wishes, or demands to each other.

The Method Holistic Participation - MHP can be advised as a convenient and effective instrument for decision-making by a team ${ }^{5,6,7}$.

\section{Design Aids as Age-Proof Housing Models}

The models give you an idea about some physical or physiological, psychological, and spiritual or mental aspects or demands of our eight chosen considerable factors. Short explanations describe the core of those design aids.

The visibly separated three paragraphs in the models give to the user indications for spiritual (at the top), psychological (in the middle), and physical (at the bottom) qualities, which have to be realized in age-proof housing.

The 8 'sub' models function as a simplified dictionary for utilizing wellbeing of dwellers.

\section{Indoor Climate}

Indoor climate - items as temperature, humidity, air quality, ventilation, light, sound, etc. supposed to be comfortable and healthy.

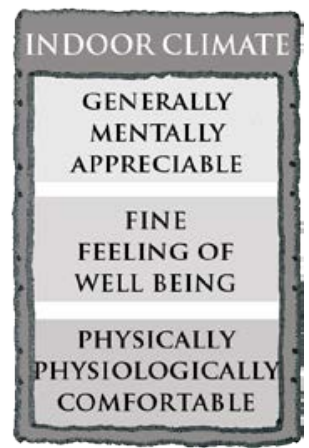

Figure 2. Design aid - Indoor climate - AHM 'sub' model

\section{Surface}

Surfaces of floors, walls, ceilings, etc. in terms of color, texture, thermal accumulation and conduction should be convenient and healthy.

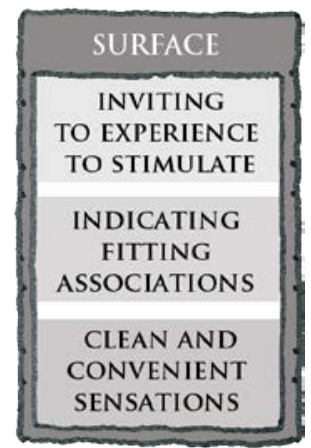

Figure 3. Design aid - Surface - AHM 'sub' model
Outlook or even better access to an outdoor area with plants, animals, people, preferably also children should be easily possible and save.

\begin{tabular}{|} 
OUTLOOK \\
UPLIFTING VIEW \\
AND ACCESS \\
TO OUTDOORS \\
NICE OUTLOOK \\
AND \\
EASY GOING \\
PRACTICAL RELATI \\
ON TO NATURE \\
NEIGHBORHOOD
\end{tabular}

Figure 4. Design aid - Outlook - AHM 'sub' model

\section{Security}

Save, secure and ergonomically proper design, layout of rooms without thresholds, save equipment, and furniture have high priorities.

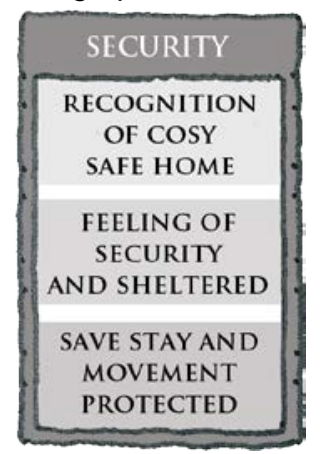

Figure 5. Design aid - Security - AHM 'sub' model

\section{Material}

All visible and invisible materials for construction and completion as well as maintenance and cleaning have to be allergic-free and toxic-free.

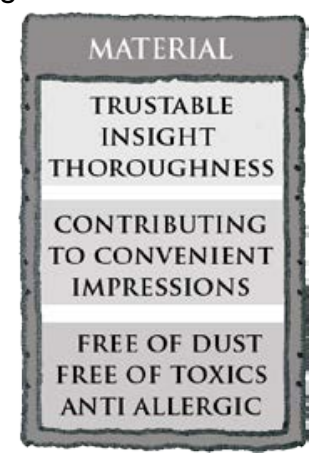

Figure 6. Design aid - Material - AHM 'sub' model

\section{Field}

An electro-magnetic neutral field is important and preferable, certainly for extra- or supersensitive people $^{4}$, and according studies of nibe - Nederlands instituut voor bouwbiologie en ecologie.

\section{Outlook}




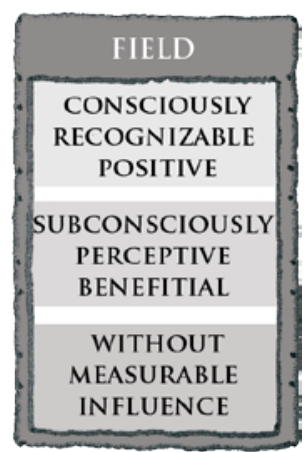

Figure 7. Design aid - Field - AHM 'sub' model

\section{Ergonomics}

Practical functionality - a suitable translation of the needs into spaces for equipment and furnishing without barriers, and accessible for wheelchair belong evidently to the demands as well as constructive flexibility.

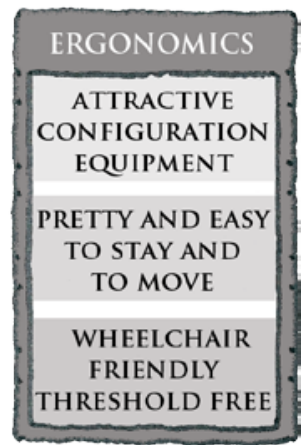

Figure 8. Design aid - Ergonomics - AHM 'sub' model

\section{Harmony}

Harmonious proportions in terms of patterns and colors should be realized except the value of a certain heritage in the interior counts higher ${ }^{2}-$ in any case there should be a pretty atmosphere.

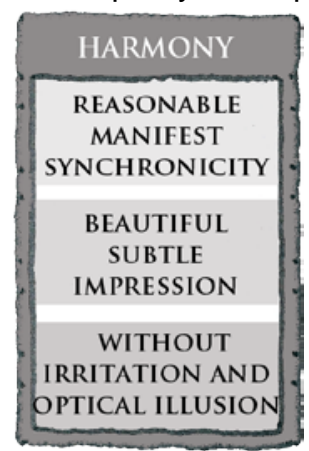

Figure 9. Design aid - Harmony - AHM 'sub' model

\section{CONCLUSION}

Some parts of this treatise might be evident. However the aim of this contribution was to pay attention also to the obviously 'natural' conditions within a building, which can support wellbeing and health for all occupants, but certainly for the aging ones. But at the same time it was the intention to include - integrally - beside the physical also the psychological and spiritual, or mental factors, which can determine the quality of life significantly. In order to make the models easily usable they follow a certain simplification of the complex interrelations of the concerned factors. Considering principles might be a better approach than (too) sharp manipulations in reaching satisfaction of the occupants.

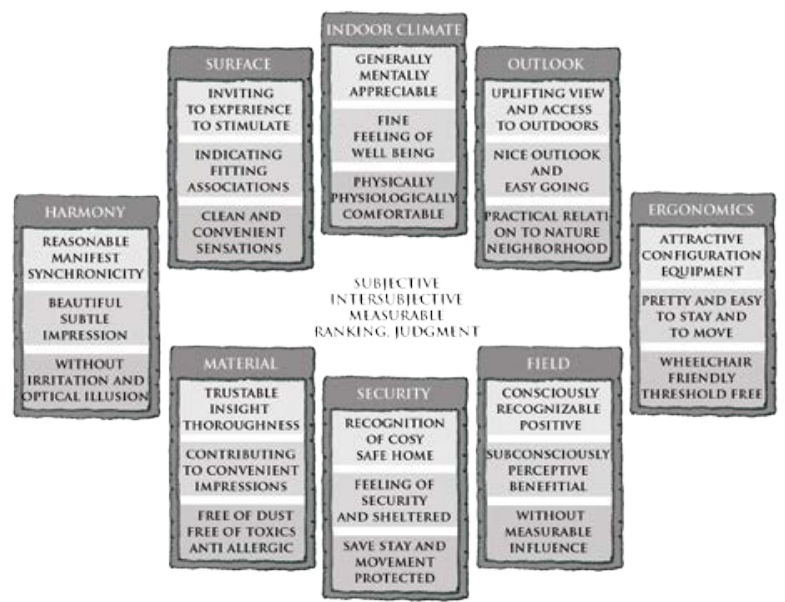

Figure 10. Integral 'Age-Proof' Housing Model - AHM

We do hope that the integral 'Age-Proof' Housing Model - AHM will help the concerned and committed persons - teachers and students included - in reaching a healthy and properly built and equipped environment.

The structure of the presented models can be easily used for developing a related computer program. Nevertheless, there always will remain most probably a certain task for wise decision-making after all calculations.

\section{References}

1. Ledegang, N., "Te weinig woningen zijn geschikt voor de oude dag", Dagblad De Pers, Donderdag 2 februari 2012.

2. Derksen, R., Cliqmakelaars "Senioren zijn erg gehecht aan hun meubilair", Dagblad De Pers, Donderdag 2 februari 2012.

3. Emmitt, S., Olie, J., Schmid, P., Principles of Architectural Detailing, Blackwell, 2004., A (in Chinese), 2006.

4. Pieper, R., "De tijd is rijp voor stralingsarme telefoons", Financieel Dagblad, Woensdag 6 juni 2001.

5. Langer, K., Metzing, M., Wahl, D., eds. "MHPO Contribution to Technology Education by $\mathrm{P}$. Schmid", Technology Education, Innovation, and Management, Springer, pp.162-168, 1996.

6. Schmid, P., Bio-Logische Architektur, Verlagsgesellschaft Rudolf Müller, 1982, 1983, 1988.

7. Wachsmann, K., The Turning Point of Building : structure and design, Reinhold Publishing Corporation, 1961. (Translation of Wendepunkt im Bauen, Krausskopf, 1959.)

8. http://www.gabriella-peterschmid-red.com 